\title{
QUEROS DE CERÁMICA Y LA PRESENCIA DEL TAWANTINSUYU EN LA CUENCA DE LOS RÍOS ACONCAGUA Y MAPOCHO, EXTREMO SUR DEL COLLASUYU
}

\author{
CERAMIC QUEROS AND THE PRESENCE OF TAWANTINSUYU \\ IN THE ACONCAGUA AND MAPOCHO BASINS, SOUTHERN END \\ OF COLLASUYU
}

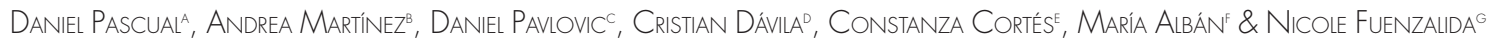

Este trabajo propone discutir las implicancias políticas y sociales de la presencia de queros en las cuencas de los ríos Aconcagua y Mapocho, centro de Chile. Se describen las características formales, iconográficas y contextuales de tres piezas cerámicas tipo queros, las únicas de esta materialidad halladas completas en Chile central hasta hoy. Estos resultados, sumados a la integración con información contextual de cada zona, sugieren que el Inka desarrolló estrategias diferenciales de interacción con las comunidades locales en ambas zonas.

Palabras clave: Collasuyu, queros, estrategias de interacción, valle del Aconcagua, cuenca del Mapocho.

This paper argues the political and social implications of the quero's presence in the Aconcagua and Mapocho river basins, Central Chile. Formal, iconographic and contextual features are described regarding three queros-type pieces, the only ones of this sort of material found complete in Central Chile so far. These results and the addition of contextual information from both zones suggest that Inka people developed different strategies of interaction with local communities in each area.

Keywords: Collasuyu, Queros, Interaction Strategies, Aconcagua Valley, Mapocho Basin.

\section{INTRODUCCIÓN}

Existe consenso en que algunas categorías de objetos habrían jugado un papel activo en las relaciones sociales que se dieron entre los inkas y las diferentes comunidades locales del Tawantinsuyu (Bray 2008; Horta 2008; Williams 2008). Estos habrían servido como mediadores y analogías materiales de los nuevos grupos de estatus generados en esta interacción, ya que, al ser poseídos, heredados y traspasados, se convertirían en significantes ideales para la posición social individual y el poder político. Esto, sumado a su restringida circulación y a su funcionamiento como parte de los sofisticados medios de registro y comunicación de alta carga simbólica que habrían sido parte de la "estrategia propagandística" inka (Ziólkowski 1996), los transformaba en bienes suntuarios muy valorados (Williams 2008; Martínez et al. 2014).

A Daniel Pascual, Departamento de Antropología, Universidad de Chile, Av. Ignacio Carrera Pinto 1045, Nuñoa, Santiago, e-mail: danipascual79@gmail.com

B Andrea Martínez, Independiente. Paicaví 51, casa 1, Valparaíso, e-mail: andreamartine@gmail.com

C Daniel Pavlovic, Departamento de Antropología, Universidad de Chile, Av. Ignacio Carrera Pinto 1045, Nuñoa, Santiago, e-mail: daniel.pavlovic@gmail.com

D Cristian Dávila, Independiente. Maquehua 2102, La Florida, Santiago, e-mail: cristiandavilac@gmail.com

E Constanza Cortés, Independiente. Vicuña Mackenna 7735, La Florida, Santiago, e-mail: c.cortes.rod@gmail.com

F María Albán, Independiente. Cardenal Newman, 1548, Las Condes, Santiago, e-mail: ma.albn@gmail.com

G Nicole Fuenzalida, Independiente. Guardiamarina Ernesto Riquelme 586, depto. 3, e-mail: nnm_fb@hotmail.com 
Los queros se contarían entre estos objetos, constituyéndose en importantes agentes simbólicos en el discurso sociopolítico de los inkas, ya que su particular forma los asemejaría conscientemente a los vasos rituales utilizados por la cultura tiwanakota y otros desarrollos culturales andinos previos (Cummins 2004, 2015; Bray 2008). En este sentido, los queros habrían cumplido un rol significativo en la legitimación de los orígenes dinásticos del Inka, así como también habrían ocupado un rol activo dentro de las estrategias de expansión territorial, siendo utilizados en contextos rituales y de banquete estatales tanto en provincias como en el Cuzco (Ziólkowski 1979; Dillehay 2003; Cummins 2004; Arriaza et al. 2015).

Si bien la etimología de la palabra quero (Ziólkowski 1979) alude directamente a la madera, en el Tawantinsuyu se registran también en otras materialidades, como metal (oro y plata) y cerámica (Bray 2008). En Chile, los estudios sobre queros se han centrado sobre todo en colecciones de piezas de madera, las cuales habrían sido recuperadas en sitios arqueológicos del Norte Grande del país (valles occidentales de Arica y desierto de Atacama), ya sea asociada a los Períodos Intermedio Tardío y Tardío o a los primeros momentos de la Colonia. Estos se han enfocado sobre todo en la interpretación de las configuraciones de sus motivos (Martínez 1986), tipologías de formas y diseños (Núñez 1963; Horta 2013; entre otros) y el análisis de los posibles productos consumidos en ellos (Arriaza et al. 2015). En el extremo sur del Collasuyu, lo que hoy comprende la zona central de Chile, no existen estudios sistemáticos sobre el tema.

En este artículo se presentan los resultados del análisis decorativo, morfológico y contextual de tres vasijas cerámicas tipo queros, las únicas de esta materialidad halladas completas hasta ahora en Chile central $\left(33^{\circ}\right.$ Lat. S.). Con ello, se pretende discutir las implicancias de su presencia para la comprensión de las estrategias diferenciales de interacción aplicadas por el Inka tanto en la zona como en el resto del Tawantinsuyu, así como el rol activo que jugaron las actividades rituales en la relación entre las poblaciones locales y el Inka.

\section{QUEROS EN EL TAWANTINSUYU}

Los queros fueron (y aún lo son) vasos rituales de significativo valor simbólico dentro del mundo andino cuyo uso estuvo (y está) estrechamente ligado al brebaje que contenían: la chicha. Aunque esta se elaboraba con diversos vegetales (algarrobo, chañar o molle, entre otros, según las tradiciones de preparación locales), el brebaje más vinculado al Inka fue el fermentado de maíz denominado aqha o aswa. Esta bebida alcohólica fue de gran importancia ceremonial y una de las ofrendas principales y más apreciadas para el Inka, junto con las llamas, el oro y la plata (Ziólkowski 1979), además del spondylus en algunos contextos (Williams 2008). El brindis con chicha y la consecuente intoxicación ritual ocurrían en todas las ocasiones ceremoniales importantes, donde el protocolo exigía brindar y beber: los servidores garantizaban el aprovisionamiento apropiado de bebidas alcohólicas para todos los comensales, quienes sentados eran servidos y tratados de acuerdo a un orden formal, su estatus y posición (Dillehay 2003).

Se ha propuesto que la práctica de embriagarse en este tipo de actividades funcionaba como un mecanismo controlador de catarsis social colectiva que relajaba las tensiones sociales de los grupos bajo la influencia del Tawantinsuyu (Saignes 1993). Asimismo, conforme al principio de reciprocidad andina, el auspicio de estos eventos generaba en los convocados una deuda, una asimetría, un compromiso y alianza que eran parte de las dinámicas usadas por el Inka para establecer y mantener su autoridad (Dillehay 2003).

Tal como relata Garcilaso de la Vega (1982 [1609]), para el inicio de las libaciones de la fiesta del Sol (Inti Raymi), el Inka se colocaba de pie delante de sus sujetos, jefes locales y otros señores principales, tomaba en seguida dos vasos de oro llenos de chicha y, como hijo mayor de la casa del Sol, su padre, inauguraba la ceremonia en su nombre. Con el vaso que sostenía en la mano derecha invitaba a beber al Sol, lo que se supone que este hacía, y luego convidaba a sus parientes. Teniendo un vaso en cada mano, el que invitaba a beber ofrecía el de la derecha a aquel personaje que fuese de mayor rango, mientras que el de la izquierda a los de menor rango. Así, se repartían la chicha en un acto recíproco de ofrecer-recibir (fig. 1).

El consumo de chicha tendría entonces funciones político-sociales muy importantes para el Estado Inka, relacionadas con la integración social (Dillehay 2003). Esto se habría logrado canalizando el flujo de las relaciones sociales, que involucraban solidaridad, reciprocidad y desigualdad social. Además, se institucionalizaría el estatus a través de los patrones implicados en el acto de beber y a través de la retórica elitista de legitimación 

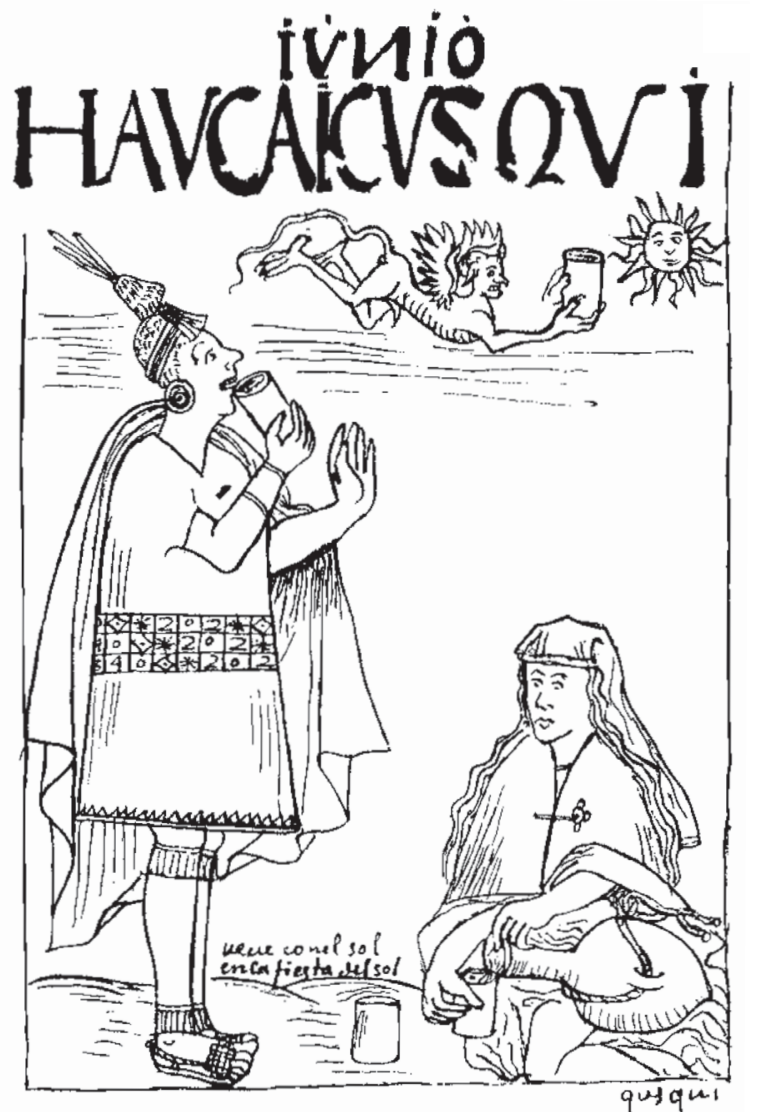

Figura 1. Dibujo de Felipe Guamán Poma (1988 [1615]). El sexto mes, junio, Haucaicusqui, bebe con el sol en la fiesta del sol. Figure 1. Drawing by Felipe Guamán Poma (1988 [1615]). June, the sixth month, Haucaicusqui, drinks with the Sun in the Sun festival.

política, con la acción y la materialidad especializada que se le asocia, como las vasijas exóticas y costosas (Dillehay 2003; Arriaza et al. 2015) de los queros.

Tal como se mencionaba, este tipo de vasos eran fabricados en oro, plata, madera, cerámica e incluso piedra. Algunos antecedentes apuntan a una probable relación entre su materia prima, el contexto de uso y/o el estatus o rango social del usuario/bebedor (Ziólkowski 1979; Liebscher 1986; Dillehay 2003; Cummins 2007). Algunos estudiosos han planteado que los vasos de arcilla se denominaban upiana (Liebscher 1986) y estarían destinados a la población común. Por su parte, los de madera eran utilizados por las "capas medias" o miembros distinguidos, mientras que los de oro y plata (estos últimos llamados aquillas) eran reservados únicamente para el Sapan Inka y para la élite (Ziólkowski 1979; Ramos 2015). En específico, el quero de oro era uno de los donativos que el Sapan Inka daba a los curacas por haber aceptado su inclusión al Tawantinsuyu o bien haber prestado algún servicio.

La desposesión de estos vasos se relacionaba con una significativa degradación de la colectividad o de la persona referente a su posición social (Ziólkowski 1979). Sin embargo, estas interpretaciones se deben tomar con cautela, ya que no necesariamente en todas las zonas del Tawantinsuyu dicha segregación de la materialidad de los vasos se dio de igual forma. Un ejemplo de ello es la capacocha del Llullaillaco, donde se recuperaron queros de madera inciso y no de metal, a pesar de ser un contexto de alta significación simbólica y política para el Inka (Ceruti 2003). En este sentido, más que la materialidad de la elaboración, pareciera ser más significativa su relación con el "brindis ritual".

Si bien existe una amplia gama de tipos de queros, su forma básica corresponde a vasos cilíndricos de diversos tamaños y perfiles, algunos acampanados (cono evertido), con base plana y borde expandido (Ziólkowski 1979; Matos 1999). Muchos de estos vasos fueron fabricados en pares o duplicados, obedeciendo a un concepto de igualdad en el acto recíproco de beber junto al huésped (Ziólkowski 1979), pero también siguiendo el principio de cosmovisión andina que dividía el mundo en dos mitades complementarias (Ramos 2015).

Las decoraciones asociadas al Tawantinsuyu de este tipo de vasos que se han documentado son las de los queros de madera, que corresponden a incisiones geométricas cuyos motivos algunos autores proponen como tocapus o proto-tocapus (Horta 2013; Ramos 2015). Su definición es variada: para algunos, corresponderían a un sistema de transmisión de información comparable a la escritura (De la Jara 1967; Barthel 1970; Ziólkowski et al. 2008) y observable tanto en queros como en tejidos. Para otros, sería una forma de comunicación gráfica de distintos tipos de información que permitiría identificar a una persona o quizás un período del año, sin ser una forma de escritura en el sentido estricto del término (Zuidema 1991; Williams 2008). Por último, otros autores proponen que se trata de una especie de heráldica del Tawantinsuyu, teniendo cada Sapan Inka sus propios emblemas (Eeckhout \& Danis 2004; Williams 2008). Así, esta iconografía geométrica podría evocar aspectos mítico-históricos relacionados con el origen del linaje inka (Cummins 2004; Lizárraga 2009; Horta 2013; Arriaza et al. 2015); en esta línea, la fusión de sus distintos atributos (forma y decoración) condensaría 
aspectos históricos de un pasado andino muy antiguo (Tiwanaku) con los de otro más reciente. Junto con otros artefactos que portan esta iconografía (aríbalos, unkus o túnicas, entre otros), los queros servirían entonces como soporte para la construcción y legitimación de la memoria dinástica inka (Arriaza et al. 2015).

En este contexto, analizaremos cómo operaría este importante objeto político-ritual inka en los lindes meridionales del Tawantinsuyu, allí donde el Inka habría interactuado con poblaciones locales cuyos sistemas sociopolíticos eran de baja desigualdad y centralismo, claramente diferenciadas de las más jerarquizadas que se hallan más cerca del Cuzco. Esta relación se daría bajo la lógica ya reconocida para otras áreas (Williams 2008): el uso de diversas y complejas estrategias de incorporación de territorios a un Tawantinsuyu en expansión.

\section{QUEROS DE CHILE CENTRAL}

La presencia del Tawantinsuyu en Chile central, sobre todo en el valle del Aconcagua y en la cuenca del río Mapocho, es territorialmente discontinua y se evidencia por medio de santuarios en altas cumbres andinas, espacios fúnebres, sitios habitacionales, una red vial, arquitectura en cimas de cerros de baja altura de carácter multifuncional (rituales, de congregación y administrativos a la vez) y arte rupestre (Sánchez 2004; Martínez 2011; Stehberg \& Sotomayor 2012; Troncoso et al. 2012; Pavlovic et al. 2012, 2014). Junto con ello, se documentan una serie de innovaciones artefactuales, como instrumentos en cobre y bronce (pinzas depilatorias, cinceles, hachas, placas, entre otras), flautas de piedra y la circulación de materias primas exóticas (p. e., obsidiana en el Aconcagua).

En la alfarería se registran nuevas formas y elementos decorativos con referentes de origen foráneo (inka y otros), en su mayoría producidos localmente y que coexisten con la continuidad de algunos tipos de vasijas de la tradición local con ligeras modificaciones morfológicas y decorativas (Vásquez 1994; Sanhueza 2001; Cantarutti \& Mera 2002; Correa et al. 20072008). Dentro del conjunto alfarero de morfología y decoración inka, son comunes los aríbalos y los platos poco profundos, dato coincidente con la propuesta de Bray (2004) sobre el equipamiento cerámico básico del Inka en provincias. La única excepción al modelo de esta autora sería la escasez de ollas con pedestales.
Bray (2003) también señala que los queros, a pesar de tener una forma común para beber, son relativamente inusuales fuera del Cuzco y se limitan a contextos muy específicos, lo que sugiere una función más especializada y limitada en esas zonas.

La escasez de estas piezas en contextos arqueológicos se repite en Chile central y está restringida a los tres vasos de cerámica que se analizan en este artículo y los siete vasos de madera que registró Mostny (1946-1947) en la tumba II del cementerio de bóvedas mortuorias de La Reina. De estos últimos, seis se encontraron asociados a lo que la investigadora denominó "sepultura simulacro" de una persona de importancia cuyas circunstancias de muerte harían imposible la recuperación del cadáver, mientras que el quero restante fue hallado junto a un esqueleto humano en la entrada del nicho (Mostny 1946-1947). Cabe mencionar que, por problemas de conservación y de acceso a las colecciones, estos vasos de madera no fueron analizados.

Además de estas piezas, hasta el momento no hay otros registros de queros de madera entre los contextos mortuorios y complejos arquitectónicos multifuncionales del Período Inka en Chile central, recuperándose sobre todo numerosas ofrendas alfareras y conjuntos cerámicos respectivamente (González \& Rodríguez 1993; Vásquez 1994; Stehberg 1995; Cantarutti \& Mera 2002; Hermosilla et al. 2002-2005; Correa et al. 2007-2008; Garceau 2009; Acuto et al. 2010; Cáceres et al. 2010; Martínez 2011; Pavlovic et al. 2012; Reyes et al. 2012; Stehberg \& Sotomayor 2012; Troncoso et al. 2012). Este hecho podría relacionarse con las condiciones ambientales de la zona, que no permitieron su adecuada conservación. ${ }^{1}$

\section{QUEROS DE CERÁMICA DE CHILE CENTRAL}

\section{Quero 1 (Sitio Complejo Arquitectónico El Tártaro, valle de Aconcagua)}

El quero 1 fue recuperado en excavaciones sistemáticas realizadas en el Complejo Arquitectónico El Tártaro (en adelante CAET) que, por contexto y organización espacial, sería uno de los principales sitios del Tawantinsuyu en Chile central (Sánchez et al. 2004; Albán 2015). Este sitio se emplaza en la cima del cerro Morro El Castillo (1.214 msnm), a unos $300 \mathrm{~m}$ sobre el nivel del valle de 


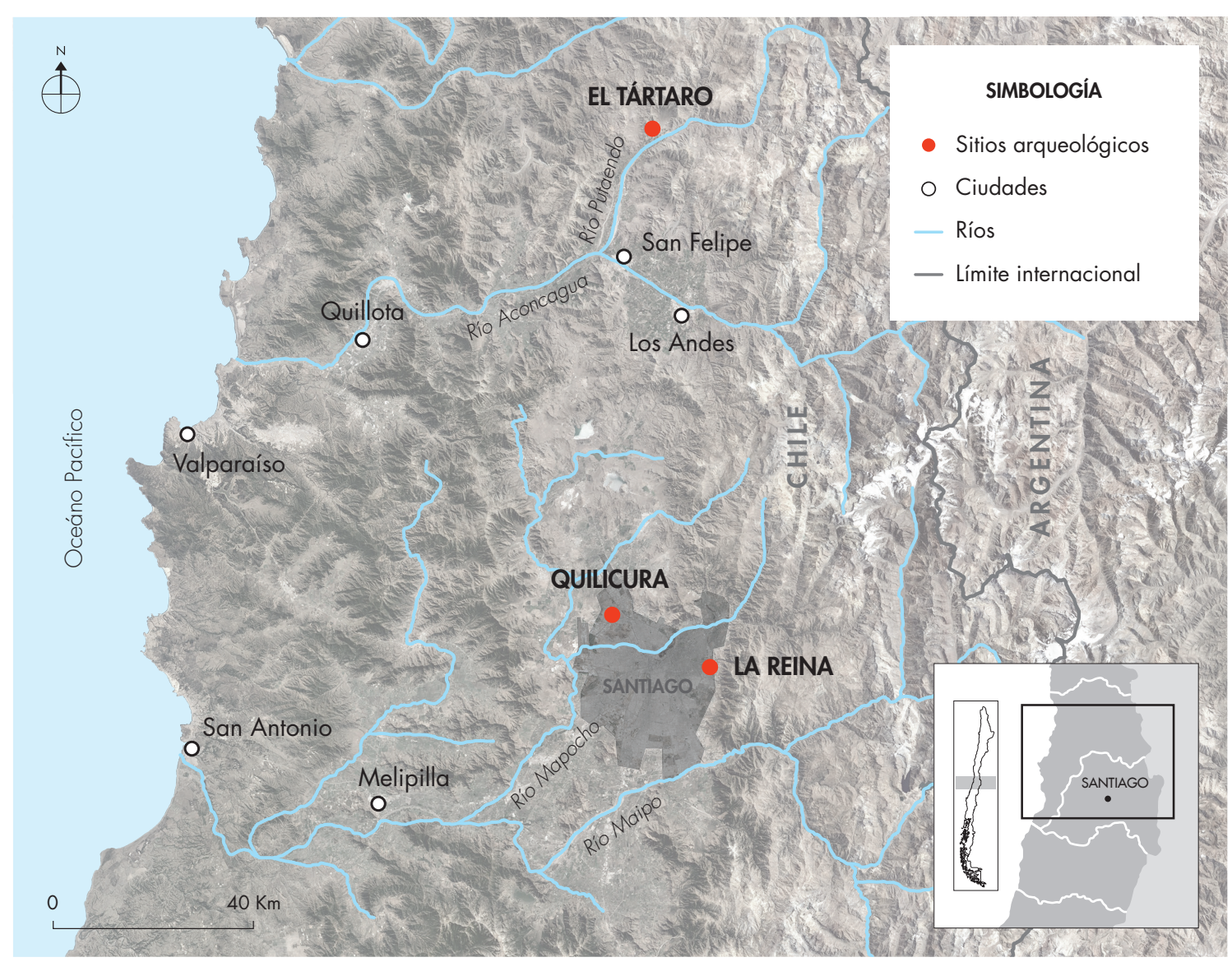

Figura 2. Mapa del valle del río Aconcagua y cuenca del río Mapocho, con sitios arqueológicos con queros de Chile central (elaborado por los autores). Figure 2. Map of the Aconcagua river valley and Mapocho river basin, including archaeological sites with queros in central Chile. Source: authors.

Putaendo, un importante tributario de la cuenca del río Aconcagua (fig. 2). ${ }^{2}$ Su visibilidad abarca gran parte de la cuenca del río Putaendo, parte de la cordillera andina y la cumbre más importante del sector, el cerro Orolonco, que habría sido sacralizada en época Inka (Pavlovic et al. 2012). En términos espaciales, el sitio se asocia a otras evidencias del período, tales como un panel de arte rupestre situado en el mismo cerro (Sánchez et al. 2004), sitios habitacionales en el valle y tramos de vialidad inka refrendados por documentos etnohistóricos (Contreras 2000); estos últimos lo conectarían con el sitio con arquitectura inka de El Tigre, a $13 \mathrm{~km}$ de distancia aproximadamente (hacia el sureste). Una batería de dos fechados por radiocarbono $(1445-1630 \mathrm{cal} \text {. DC })^{3}$ y siete por termoluminiscencia (1360-1580 DC) ${ }^{4}$ (Pavlovic et al. 2012, 2013) lo sitúan en fechas coincidentes con el período en cuestión.
El sitio presenta una clara planificación y organización espacial de tipo segregada de sus recintos y actividades. Esto es evidente por el reconocimiento de tres sectores principales, con un total de 25 estructuras circunscritas (incluyendo posibles bases de colcas) por un gran muro perimetral, abarcando cerca de 17.000 $\mathrm{m}^{2}$ (Letelier 2010; Pavlovic et al. 2013). El Sector 1 es el de mayor jerarquía dentro de la estructura espacial del sitio (Albán 2015), al emplazarse en la zona central y más alta del mismo y poseer un muro perimetral concéntrico interno que restringe el acceso y un conjunto de estructuras que rodean un espacio limpio de estructuras, la "plaza central".

Desde este sector se habrían planificado, organizado y articulado el conjunto de recintos y las actividades desarrolladas en el sitio. Estas se relacionarían sobre todo con eventos ceremoniales y de congregación social 
no cotidianos en los cuales habrían participado miembros de las comunidades que tenían sus asentamientos permanentes en las zonas aledañas bajas.

El vaso cerámico tipo quero hallado en este sitio (en adelante, quero 1) se encontró fracturado pero completo, y correspondería a un depósito "de facto" (posible ofrenda) realizado en uno de los recintos más próximos a la "plaza central" del sector 1 (fig. 3), a 32 $\mathrm{cm}$ de profundidad. Además, en este recinto se advirtió la presencia, a partir de la fragmentería, de al menos 10 piezas cerámicas de estilo Inka, Diaguita, rojos engobados y monocromos. Ninguna de ellas es de tradición local, lo que demuestra una concentración exclusiva y segregada de ciertos tipos de piezas con referentes foráneos, a diferencia de lo observado en otros recintos donde aparecen en forma mayoritaria vasijas propias de la tradición local y son muy escasas las piezas de estilo Inka (Albán 2015). Además, se encontró un único fragmento de plato lítico con decoración incisa y un fragmento malacológico, de baja frecuencia en el sitio.

De este modo, el quero sería parte de un contexto de alto capital simbólico para el Inka registrado en un recinto aledaño a la plaza central, que habría tenido un rol significativo en el funcionamiento del sitio y una mayor jerarquía en relación a otros recintos del complejo arquitectónico, conectado espacialmente a la plaza y de acceso restringido. En este sentido, el hallazgo de esta vasija completa podría aludir a actividades rituales de alta relevancia que, dadas las características de la estructura donde se halló, habrían sido eventos más bien privados, con la congregación de un número acotado de personas (Albán 2015) que habrían compartido comida y bebidas, probablemente chicha. Evidencia de esta última afirmación es la presencia de almidones de maíz, quínoa y algarrobo en el interior del quero (Belmar et al. 2013).

Con respecto a las características específicas del quero 1 , este corresponde a una vasija no restringida, simétrica de perfil simple, con ambas caras pulidas. $\mathrm{Su}$ cuerpo es cilíndrico, de borde evertido, labio redondeado y paredes de espesor mediano, además de una base plana. Es de tamaño pequeño, superando por poco los $75 \mathrm{~mm}$, y de volumen bastante acotado (ver detalle en la tabla 1). Posee decoración polícroma por el exterior, mientras que presenta rojo engobado en toda su superficie interior. La decoración externa se compone de un engobe blanco en su labio, borde y cuerpo, y engobe rojo en su base. Sobre el engobe blanco se distinguen diferentes motivos en cada sección de la vasija.

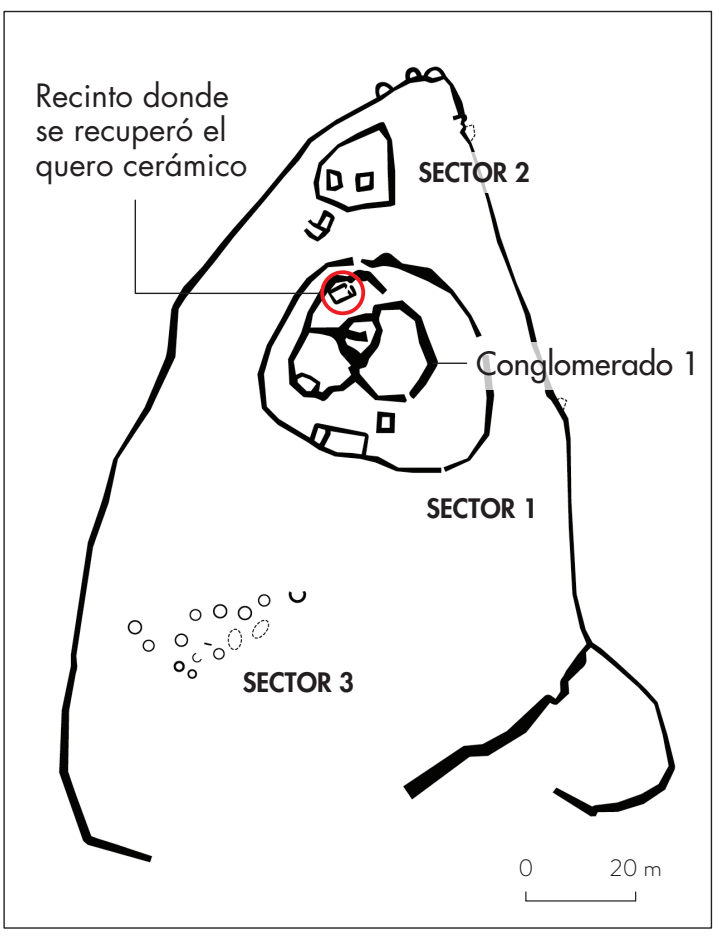

Figura 3. Plano topográfico del Sitio Complejo Arquitectónico El Tártaro 1. Figure 3. Topographic map of the Architectural Complex El Tártaro 1 Site.

En el borde se observa una franja negra horizontal unidireccional, mientras que el cuerpo expone dos bandas horizontales (organización dual): la primera ocupa la sección superior del cuerpo, donde dos líneas negras paralelas horizontales delimitan un campo de cuatro franjas de dos rombos concéntricos en hilera (Fernández Baca 1971); de estas, la primera y la última son de color rojo; las del centro, negras. En la sección media del cuerpo, entre las bandas, hay una franja negra horizontal unidireccional que rodea todo el cuerpo.

La banda inferior se compone de dos franjas, una superior y otra inferior (organización dual), compuestas a su vez por un diseño de rectángulos rellenos de color (negro y rojo) separados por un rectángulo que contiene líneas quebradas (Fernández Baca 1971) paralelas, formando un zigzag horizontal de color negro y una franja vertical del color del engobe (blanco). El patrón de color hace un juego de dos rectángulos rellenos de pintura negra y uno de color rojo. Esta franja horizontal se repite inmediatamente debajo pero con un principio de traslación del diseño, donde bajo el rectángulo de color se dispone el campo de diseño zigzag. El diseño 


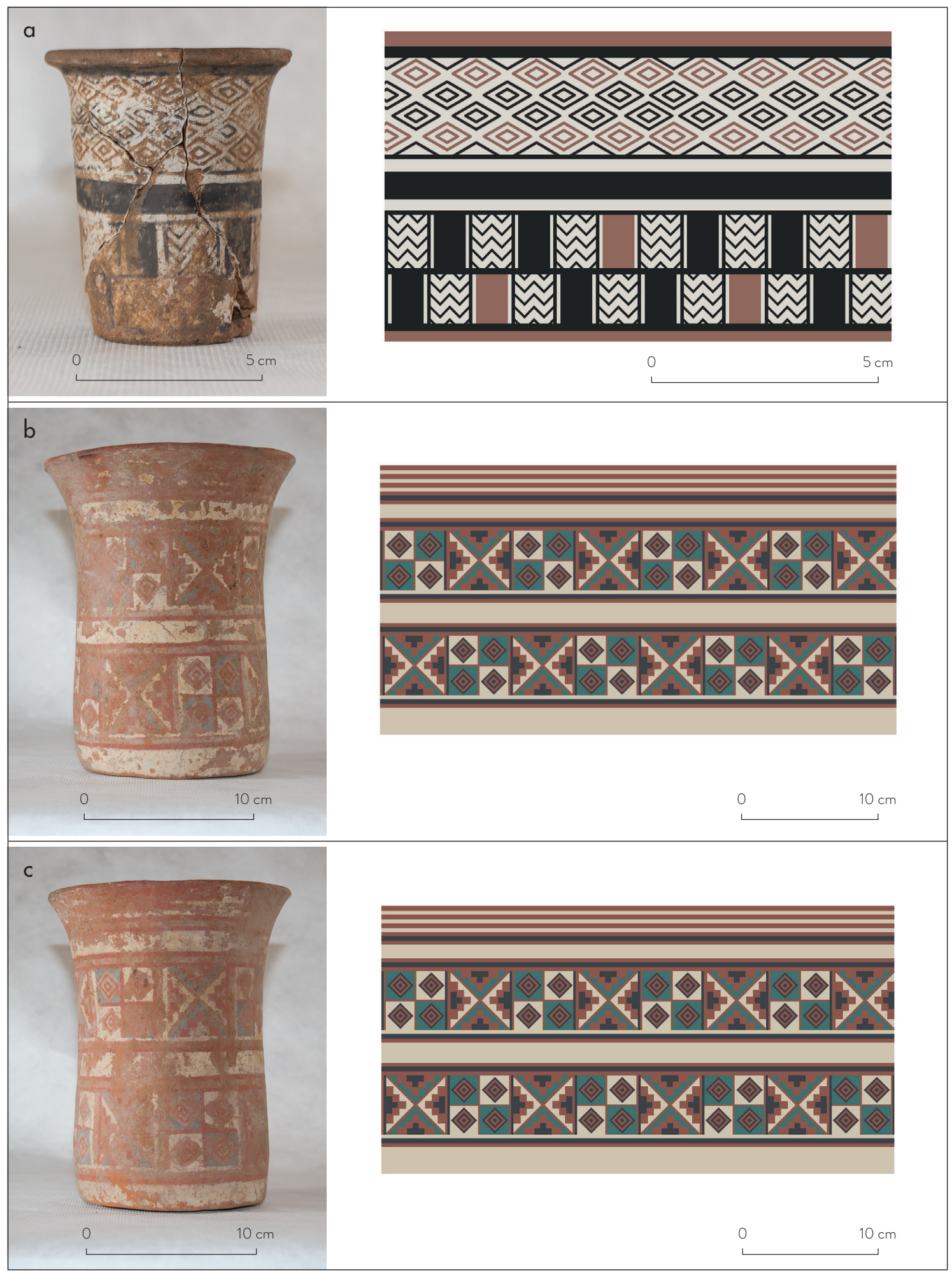

Figura 4. Izquierda: imágenes de las vasijas. Derecha: los diseños decorativos respectivos: a) quero 1; b) quero 2; c) quero 3 . Figure 4. Left: images of the vases. Right: with their respective decorative patterns: a) quero $1 ; \boldsymbol{b}$ ) quero 2; $c$ ) quero 3. 
que se genera con la tríada del patrón de los colores de los rectángulos rellenos (negro, negro y rojo) e intercalados por los rectángulos con el zigzag horizontal sería la unidad mínima para conformar el motivo de la banda inferior (fig. 4).

En resumen, podemos indicar que el quero 1 habría sido utilizado y luego depositado a modo de ofrenda en el marco de prácticas rituales de congregación vinculadas a las dinámicas de interacción entre el Tawantinsuyu y las poblaciones locales desarrolladas en uno de los principales sitios inkaicos del valle, el CAET.

\section{Queros 2 y 3 (sitio Quilicura 1, cuenca del río Mapocho)}

Los queros 2 y 3 fueron recuperados en excavaciones sistemáticas realizadas en el sitio Quilicura 1, situado en la localidad del mismo nombre que es parte de la cuenca norte del río Mapocho, tributario del río Maipo (fig. 2). Quilicura corresponde a un sitio funerario que ha sido objeto en dos oportunidades de actividades de salvataje arqueológico, a raíz de la ejecución de obras de excavación para instalación de alcantarillado. Durante su identificación original, fue posible distinguir al menos cuatro inhumaciones, las cuales se registraron asociadas a 30 vasijas alfareras tanto de estilo Inka (aríbalos y escudillas bajas), como locales de Fase Inka (escudillas y jarros) y de tradición local de origen preinkaico (una escudilla Aconcagua Negro sobre Salmón) (Stehberg 1976).

Debido a obras de excavación realizadas en un terreno particular aledaño a la zona estudiada previamente, fue identificado y sometido a actividades arqueológicas durante el año 2014 otro contexto mortuorio, denominado tumba 5 del sitio Quilicura 1 (Pavlovic et al. 2016). Entre los 150 y $200 \mathrm{~cm}$ de profundidad, se registró un contexto fúnebre constituido por la inhumación de un individuo femenino de entre 20 y 35 años de edad que fue depositado extendido decúbito dorsal y que presentó 26 piezas alfareras como ofrendas.

La datación absoluta obtenida sobre muestras de este individuo lo sitúa entre 1.441 y $1.616 \mathrm{cal}$. DC, ${ }^{5} \mathrm{y}$ los estudios isotópicos apuntan a una dieta mixta, que incluía vegetales domesticados (maíz) o suculentas (C4), vegetales silvestres (C3) y carne. Otra datación obtenida en un hueso de anura recuperado del interior de una vasija de ofrenda entregó una datación distinta para el contexto, de entre 1.420 y 1.467 cal. DC. ${ }^{6}$
Tabla 1. Medidas generales de los queros.

Table 1. General measures of the queros.

\begin{tabular}{|c|c|c|c|}
\hline & CAET & \multicolumn{2}{|c|}{ QUILICURA 1} \\
\hline CARACTERÍSTICA & QUERO 1 & QUERO 2 & QUERO 3 \\
\hline Altura máx. ${ }^{*}$ & 76,7 & 189 & 186 \\
\hline Altura cuerpo* & 76,7 & 189 & 186 \\
\hline Altura diámetro máx.* & 76,7 & 189 & 186 \\
\hline Diámetro borde ${ }^{\star}$ & 48,3 & 153 & 145 \\
\hline Diámetro base $e^{*}$ & 43 & 110 & 107 \\
\hline Volumen (ml) & 90 & 1640 & 1620 \\
\hline Espesor labio* & 3,2 & 4,5 & 3,8 \\
\hline Espesor borde* & 4,5 & 5,3 & 4,5 \\
\hline Diámetro min.* & 43 (base) & 110 (base) & 107 (base) \\
\hline Peso (gr) & 106,1 & 845 & 715 \\
\hline
\end{tabular}

*Medidas en milímetros.

En su mayoría, las vasijas recuperadas en este contexto corresponden a las mismas categorías ya identificadas en el primer salvataje y varias de ellas se presentaban como piezas pareadas o gemelas. Entre estas, se contaban dos significativas piezas que no habían sido registradas antes en el sitio y prácticamente en todo Chile central: dos grandes queros profusamente decorados (en adelante queros 2 y 3 ). Estos fueron recuperados en un conjunto de ofrendas cerámicas depositadas a los pies del individuo inhumado, junto a un par de aríbalos, varias escudillas bajas, una gran olla y otras vasijas (figs. 5 y 6 ).

El análisis morfológico, iconográfico y tecnológico permitió establecer que el conjunto alfarero podía subdividirse entre: piezas de estilo Inka (aríbalos, aysanas y escudillas bajas), piezas locales de Fase Inka (escudillas y jarros) y piezas Diaguita-Inka (dos vasijas urniformes gemelas), destacando dentro del primer conjunto la presencia de dos queros. De manera preliminar, todo apuntaría a que las piezas de estilo Inka y las locales de 


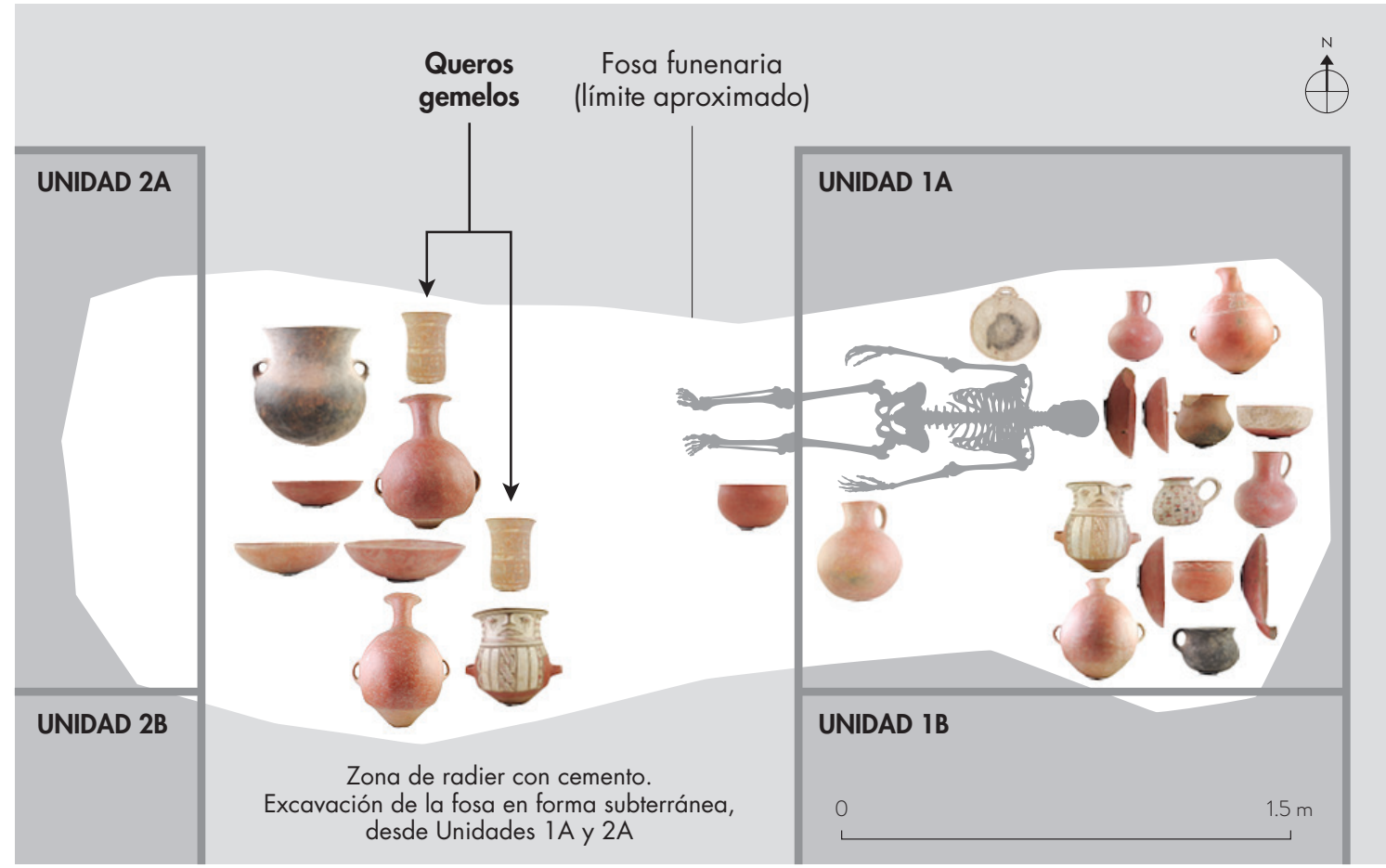

Figura 5. Disposición esquemática de ofrendas cerámicas en tumba de sitio Quilicura 1. Se indica la ubicación de los queros gemelos (elaborado por los autores). Figure 5. Schematic disposition of ceramic offerings in the tomb of Quilicura 1 site. Position of twin queros shown here. Source: authors.

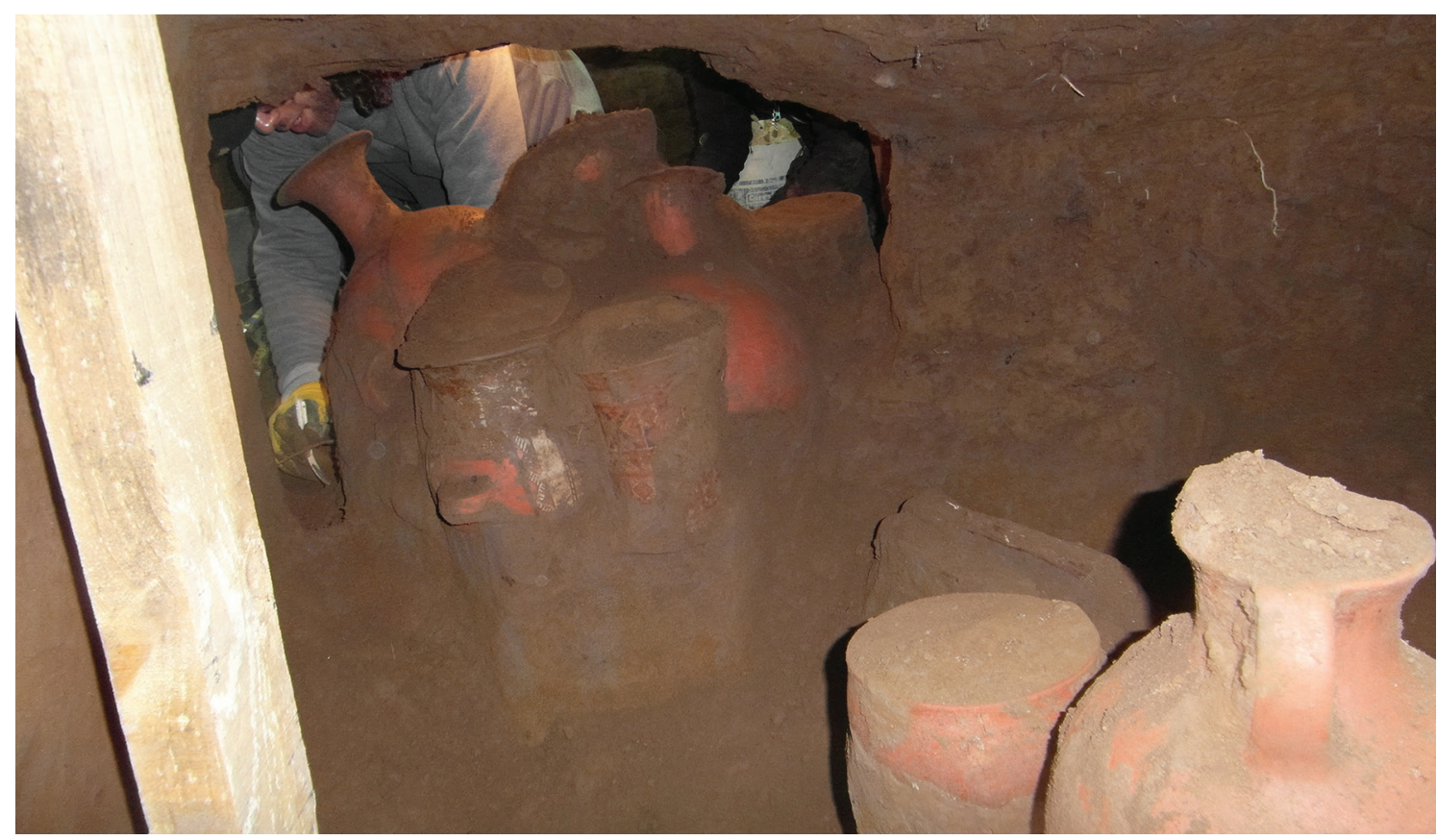

Figura 6. Detalle de ubicación de los queros en conjunto de ofrendas cerámicas ubicadas a los pies del individuo inhumado en la tumba 5 del sitio Quilicura 1. Se aprecia excavación subterránea de fosa funeraria. Figure 6. Detail of the location of the queros among other ceramic offerings at the feet of the buried individual in the gravesite 5 of Quilicura 1 site. Excavation of burial site depicted here. 
Fase Inka serían de producción local, a excepción de los queros y las Diaguita-Inka, que podrían ser de producción foránea o bien piezas producidas y decoradas con técnicas y/o materias primas diferentes a las de los otros conjuntos.

Por su parte, los análisis arquebotánicos (Belmar et al. 2015) ejecutados en las vasijas permitieron establecer que ambas fueron usadas para el consumo de chicha de maíz (almidones y silicofitolito de Zea mays). De 16 piezas muestreadas, solo estas portaban microfósiles asociables a maíz, mientras que en otras se identificó quínoa, poroto, papa, ají y leguminosas silvestres.

Los queros 2 y 3 corresponden a vasijas hermanas (pareadas), de tipo no restringida, simétricas de perfil inflectado, con ambas caras pulidas, de cuerpos cilíndricos, bordes evertidos, labios redondeados y paredes de espesor mediano, además de una base plana. Su métrica es casi la misma, de gran tamaño: superan los $180 \mathrm{~mm}$ de altura y tienen un volumen considerable (ver detalle en tabla 1). Su configuración decorativa también es semejante: ambos queros son polícromos por el exterior y presentan rojo engobado en la totalidad de su superficie interior. La decoración externa se compone de engobe rojo en toda la pieza, sobre el cual se disponen tres franjas de engobe blanco delimitadas por líneas rojas y negras que, a su vez, delimitan tres bandas decoradas por diferentes motivos (organización tríadica).

La primera banda decorada se observa en el borde, con siete líneas paralelas horizontales, unidireccionales y alternadas en rojo (4) y blanco (3). Bajo esta, en la unión del borde evertido con el cuerpo se ubica la primera franja de engobe blanco, bajo la cual está la segunda banda con motivos, delimitada superiormente por una línea horizontal unidireccional roja e inferiormente por una blanca. Esta banda cubre la sección superior del cuerpo y está compuesta por dos campos de diseños de forma cuadrada que se repiten en serie de manera horizontal cuatro veces alrededor de la pieza. Ambos campos están divididos en cuatro.

El primer campo muestra una división cuatripartita a partir de una línea vertical y otra horizontal, dejando cuatro subcampos, dos de color blanco y dos celestes que se oponen por el vértice, donde se muestran cinco rombos concéntricos (Fernández Baca 1971) rojos y negros de manera alternada. El segundo campo está dividido por dos líneas diagonales, generando también cuatro subcampos, pero esta vez de forma triangular, dos de ellos blancos y dos celestes, también opuestos por el vértice. En cada subcampo se aprecian dos figuras escaleradas (Fernández Baca 1971) superpuestas, uno rojo de tres escalones en cuyo interior hay uno negro de dos escalones.

En la sección inferior del cuerpo, separados por la segunda franja blanca, se exhibe la segunda banda, con la misma delimitación, los mismos campos y subcampos de diseño, pero presentándose de forma alternada. Finalmente, bajo esta banda se encuentra la tercera franja de engobe blanco, en la parte inferior del cuerpo. Cabe destacar que la única diferencia en los diseños de ambas vasijas es el color de los subcampos cuadrados donde se ubican los rombos concéntricos, que se presentan de forma alternada en cada vasija (fig. 4).

\section{DISCUSIÓN}

Tal como los actuales, los contextos rituales andinos del pasado histórico o prehispánico constituyeron un todo relacional, dinámico y multisensorial (sonoro/ auditivo, táctil, visual, aromático), un sistema de comunicación y registro altamente complejo (Martínez et al. 2014). Comprender su estructura, funcionamiento y significado es una labor compleja que debe ser asumida considerando todos sus aspectos de forma integrada y contextual (Martínez 1986; Cummins 2015). Un buen ejemplo son los queros, pues estas piezas expresan lo multidimensional del mundo andino, como objetos cargados y portadores de significados sociales, económicos, políticos, rituales y simbólicos.

En el caso particular del Tawantinsuyu, los queros y su forma estandarizada, independiente de su materialidad, son una expresión recursiva del Inka, que darían cuenta tanto de su poder político-ritual como de su relato mítico-histórico. Dicha unificación visual y material hace que estos vasos sean emblemas o esquematizaciones simbólicas del Tawantinsuyu, ya que es indisoluble la integridad entre apariencia y sustancia (Cummins 2015).

Lo anterior nos lleva a reflexionar sobre las implicancias de la presencia de este tipo de vaso en los límites más australes del Collasuyu, sobre todo considerando su estrecha relación con el poder y la ritualidad del Tawantinsuyu, pues no solo es un bien exótico y escaso, sino que no formaría parte del inventario cerámico más recurrente fuera del área del Cusco (Bray 2004).

Los vasos cerámicos hallados en esta zona no son monocromos, como la mayoría de los queros cerámicos. 
Autores como Flores Ochoa et al. (1998) proponen que la policromía solo aparecería en los queros de madera durante el Período Colonial, no documentándose este tipo de decoración en vasijas cerámicas precolombinas. Sin embargo, por muy escasos que sean, sí existen ejemplares de esta materialidad con este tipo de decoración en contextos previos al contacto hispano (Williams 2008; Ramos 2015). Así, al considerar la decoración de las tres piezas descritas en la sección anterior, reconocemos una iconografía geométrica muy similar a las de los queros de madera y textiles (p. e., unkus), las cuales han sido interpretadas como tocapus o proto-tocapus que funcionaron como emblemas portables del Estado, ya sea como signos heráldicos, estatus del portador o recordatorios de hechos, hazañas, lugares o alianzas entre el Inka y líderes locales (Ziólkowski 1979; Horta 2013; Martínez et al. 2014; Ramos 2015). Además, la disposición de los campos decorativos de estos queros se rige bajo los principios andinos de organización bi, tri y cuatripartita (fig. 4). La presencia y estructuración de estos motivos en las piezas es muy significativa y apoya la idea de la importancia que tuvo para el Tawantinsuyu plasmar e incorporar en estas latitudes elementos de su ritualidad y sus relatos mítico-históricos, ya que a través de su uso y manejo se intentaría ejercer el dominio simbólico y la anexión de las comunidades locales al Tawantinsuyu (Acuto et al. 2010; Troncoso et al. 2012).

Ahora bien, su incorporación en las cuencas del Aconcagua y Mapocho implicaría algo más que lo recién descrito; nos hablaría de la realización de rituales propios y de alta significancia para el Inka. Aun cuando las evidencias de que disponemos no permiten hablar con propiedad de la realización de festines y ceremonias descritas para los Andes centrales y su periferia más cercana (Dillehay 2003; Arriaza et al. 2015; Ramos 2015), sí es posible afirmar al menos parte de estas, como sería la de beber chicha en queros, muy probablemente bajo parámetros rituales similares a los descritos para otras áreas.

En el caso del CAET en el valle del Aconcagua, el hallazgo de este tipo de vasija completa se ha propuesto como evidencia de eventos rituales con una fuerte impronta política, en un sector y recinto de gran importancia dentro de la configuración del sitio en cuanto a arquitectura y actividades realizadas (Albán 2015). Es importante destacar que la relevancia de esta pieza no se debe a su ubicación geográfica, sino que es el uso y depósito del quero el que le otorga buena parte de su importancia a este sector del sitio.
Asimismo, cabe remarcar el pequeño tamaño de esta pieza en comparación con los queros de la cuenca del río Mapocho. El dato coincide con lo expuesto por Flores Ochoa et al. (1998), según quienes los queros de menor tamaño estarían destinados al uso del Inka y sus ofrendas. Reconociendo la conformación jerárquica de la arquitectura del sitio (Albán 2015), la evidencia del quero 1 asociado a otras vasijas de referentes foráneos (Inka y Diaguita) podría dar luces sobre actividades ceremoniales de comensalismo político en espacios de accesos restringidos en el sector 1, esto es, la participación de grupos pequeños y selectos de comensales o bien su uso por parte de un individuo particular, en un contexto en donde los referentes foráneos primarían. Esto difiere de lo observado en otros sectores del CAET, donde las restricciones de acceso son menores y se halla evidencia material con referentes más locales (tipo Aconcagua Salmón, ${ }^{7}$ Putaendo rojo sobre Blanco), sugerencia de una participación más abierta. Ello concuerda con lo propuesto para otros espacios ceremoniales de complejos arquitectónicos de altura en estos valles, donde se compartiría bebidas y comidas entre los representantes del Tawantinsuyu y los líderes locales en el marco de festividades del calendario cusqueño vinculadas a los solsticios de verano y/o invierno (Martínez 2011; Troncoso et al. 2012).

Por otro lado, en la cuenca del río Mapocho, el hallazgo de una pareja de queros dentro de un entierro podría referir al rito andino de "comer con el difunto", en que la vasija se incorpora como ofrenda con los alimentos que más gustaban al fallecido. Tal ceremonia se ha planteado para contextos funerarios del Norte Grande de Chile (Arriaza et al. 2015) y para momentos más tardíos en crónicas y en estudios etnográficos (Hastorf 2003). A esto se suma que su hallazgo se dio junto a vasijas pertenecientes a distintas tradiciones alfareras, lo que apuntaría no solo al prestigio del individuo y/o del linaje al que pertenecía, sino también a un contexto de particular importancia para el desarrollo de actividades rituales, asociadas al mismo tiempo tanto a los cultos introducidos por el Inka, como a las formas de interacción diplomática con las poblaciones locales que el Tawantinsuyu utilizó en la zona. Cabe destacar además la presencia de aríbalos entre las ofrendas, que junto a los queros evidencian la presencia de un complejo material relacionado con el brindis y la libación ritual. Estos elementos estarían enmarcados en uno de los eventos más significativos de agregación social para 
las comunidades locales ya documentado en momentos previos a la llegada del Inka: las ceremonias fúnebres.

El hecho de que estos queros estén pareados, posean la misma forma y casi idéntica decoración es algo recurrente en este tipo de piezas, y podría ser reflejo de la división dual de la pareja humana (femenina y masculina) (Ramos 2015), del brindis ritual como metáfora de la reciprocidad andina (Ziólkowski 1979) y, en términos generales, de la cosmovisión andina.

Los contextos particulares de hallazgo de estos queros cerámicos muestran notables diferencias. Por una parte, tenemos el vaso de tamaño reducido encontrado en el CAET, mientras que los queros duplicados de gran tamaño del sitio Quilicura 1 formaban parte de las ofrendas cerámicas $(\mathrm{N}=26)$ del enterratorio de un individuo femenino adulto. Las diferencias de tamaño de los vasos, tipo de asentamiento, emplazamiento de los sitios (cumbre de cerro v/s valle) y manejo visual de estos son elocuentes. Sin embargo, ambas piezas muestran similitudes en cuanto al rol y peso simbólico, ya que le otorgan una importancia singular a los espacios particulares en donde fueron depositadas. Además, en los sitios donde fueron recuperadas se llevaron a cabo las ceremonias comunitarias y públicas ya descritas.

En este marco, es de particular significación el hecho de que los otros queros del valle del río Mapocho hayan sido encontrados en un contexto funerario de características singulares y sin parangón en la zona: las tumbas abovedadas de La Reina (Mostny 1946-1947), donde se registraron siete queros de madera. Ello reafirma la idea de que estas piezas son parte de contextos muy singulares.

Lo anterior nos permite plantear que, a pesar de existir elementos comunes, como algunos tipos cerámicos o la presencia de capacochas en cumbres significativas (Aconcagua y cerro El Plomo), que indicarían la vigencia de los mismos principios ideológicos inkaicos de comprobada eficacia política en ambas zonas, también se dieron estrategias de dominio simbólico y relacional diferenciales entre estas. Pareciera ser que, en la cuenca del Aconcagua, el Inka centra su accionar en los complejos arquitectónicos, los espacios de altura y el arte rupestre (Pavlovic et al. 2012; Troncoso et al. 2011, 2012), teniendo un menor impacto y visibilidad en el ámbito funerario. Por su parte, en la cuenca del Mapocho la ocupación y/o instalación de arquitectura sobre cumbres y estribaciones de cerros no se ha identificado, y el arte rupestre es sumamente escaso. Esto es llamativo, dado que hacia el sur, en el valle del Maipo, la arquitectura en cerros es muy importante y representativa de la presencia inka (Stehberg 1995; Stehberg \& Sotomayor 2012).

En ese marco, en la zona norte de la cuenca del Mapocho se evidencia un gran esfuerzo por mostrar la influencia y los emblemas del Tawantinsuyu en los espacios mortuorios (Sánchez 2003), al constatar que el numeroso y diverso despliegue de ofrendas cerámicas evidenciado en la tumba 5 del sitio Quilicura 1 no es un caso aislado en el contexto de las manifestaciones funerarias del Período Inka. De esta manera, sitios con significativas cantidades de vasijas como ofrendas mortuorias se presentan en Quilicura (Las Tinajas, Parcela 24 y Talleres y Cocheras), Lampa (El Almendral, Pablo Carvajal), Colina (Peldehue) y en las zonas norte y noreste de la ciudad de Santiago (Estación Intermodal, Carrascal, La Reina, Marcoleta, Jardín del Este) (Mostny 1947; Madrid \& Gordon 1964; Thomas et al. 1990; González \& Rodríguez 1993; Hermosilla et al. 2002-2005; Cáceres et al. 2010; Reyes et al. 2012; Mankuk 2015).

Todo esto no solo es manifestación de una relación diferencial con la población local, sino también de estrategias singulares que posiblemente se vinculan con intereses distintos por parte del Tawantinsuyu y/o respuesta a formas de organización social o tradiciones culturales previas diferentes para ambas cuencas, lo que habría generado dinámicas de interacción particulares (Pavlovic et al. 2012, 2014; Falabella et al. 2016). Ello no es de extrañar, ya que la adecuación de las estrategias fue algo recurrente en el proceso de expansión territorial del Inka (Hayashida 2003; Perales 2004; Alconini 2008; Williams 2008; Acuto et al. 2010).

No obstante lo anterior, la presencia de estos queros se da en el marco de contextos de amplia convocatoria, tanto en una dinámica sin antecedentes previos (complejos arquitectónicas sobre cumbres de cerros), como en otra con profundos antecedentes locales (ceremonias funerarias). Es muy probable que, en ambos casos, los aspectos rituales vinculados al consumo, brindis y libaciones de chicha de maíz en queros se hayan interrelacionado con dinámicas de interacción entre los representantes del Tawantinsuyu y las poblaciones locales (Pavlovic et al. 2016).

En ese sentido, y como se ha indicado previamente, las dinámicas rituales en períodos asociados a la presencia inka deben ser evaluadas en sus contextos locales, ya que es ahí donde toman su forma y significado específico. Todos estos actos y elementos de la ritualidad inkaica 
tienen expresiones locales diversas en las distintas áreas del Tawantinsuyu, debido a que se definen en la relación e interacción con los grupos locales y sus propios mundos simbólicos a través de las prácticas cotidianas y de las performances rituales colectivas (Cummins 2015).

RECONOCIMIENTOS Los autores agradecen a la familia Valenzuela y a la Sociedad Agrícola y Ganadera Tongoy por las facilidades y autorizaciones para el desarrollo de los estudios en los sitios Quilicura 1 y CAET, respectivamente. Del mismo modo, agradecen a todos los estudiantes y colegas que participaron en las excavaciones de ambos sitios. A Eduardo Elgueta Strange por la elaboración de las figuras sobre la decoración de los Queros, a Francisca Campos Álvarez por las labores de limpieza, conservación y embalaje de las vasijas y a Juan Hermosilla por su colaboración en el análisis de las piezas de Quilicura. A Rodrigo Sánchez y a Andrés Troncoso por sus invaluables comentarios y correcciones al presente artículo. Finalmente, a la Comisión Nacional de Investigación Científica y Tecnológica por financiar el proyecto en que se inserta el presente trabajo (FONDECYT 1140803) y al Consejo de Monumentos Nacionales por autorizar los trabajos arqueológicos en ambos sitios.

\section{NOTAS}

${ }^{1}$ Las piezas de La Reina se conservaron gracias a las condiciones particulares de depositación (tumba abovedada) que habrían evitado su descomposición.

${ }^{2}$ Administrativamente pertenece a la Comuna de $\mathrm{Pu}-$ taendo, Provincia de San Felipe, v Región de Valparaíso.

${ }^{3}$ UgAMS 13135, calibrada por OxCal v4 2.4, rango 1: $1445-1516$ cal. DC $(p=80,7 \%)$ y rango $2: 1597-1618$ cal DC ( $p=14,7 \%$ ) y UGAMs 13134 , calibrada por OxCal v4 2.4, rango 1: $1451-1523 \mathrm{cal} \mathrm{DC}(p=62,3 \%)$ y rango $2: 1572-1630 \mathrm{cal}$ DC $(p=33,1 \%)$

${ }^{4} 1360 \pm 60$ DC (UCTL 1253), 1370 \pm 50 DC (UCTL 1250), $1400 \pm 50$ DC (UCTL 1249), 1445 \pm 60 DC (UCTL 1252), $1500 \pm 40$ DC (UCTL 1255),1520 \pm 50 DC (UCTL 1254), $1580 \pm 40$ DC (UCTL 1251).

${ }^{5}$ UGAMS 20317, calibrada por OxCal v4 2.4, rango 1 : 1441-1512cal DC $(p=86,8 \%)$ y rango $2: 1601-1616 \mathrm{cal}$ DC $(p=8,6 \%)$.

${ }^{6}$ UGAMS 20316, calibrada por OxCal v4 2.4, $p=95,4 \%$.

${ }^{7}$ Cabe destacar que el tipo Aconcagua Salmón es una variedad alfarera casi ausente en el sector de Putaendo; sin embargo, es bastante usual en los cursos medios y bajos del valle de Aconcagua y en Chile central en general.

\section{REFERENCIAS}

Acuto, F.; A. Troncoso, A. Ferrari, D. Pavlovic, C. Jacob, E. Gilardenghi, R. Sánchez, C. Amuedo \& M. Sмiтh, 2010. Espacialidad incaica en los Andes del sur: la colonización simbólica del paisaje y la ritualidad Inka en Chile central y el valle Calchaquí norte. En Actas del XVII Congreso Nacional de Arqueología Argentina, tomo III, pp. 1297-1302. Mendoza.

Albán, M., 2015. Funcionalidad de sitios y su rol en las dinámicas de ocupación Incaica en el valle de Aconcagua, Chile central (1450-1536 D.c.): aportes desde la alafrería. Memoria para optar al Título de Arqueóloga, Departamento de Antropología, Facultad de Ciencias Sociales, Universidad de Chile.

Alconini, S., 2008. Dis-embedded centers and architecture of power in the fringes of the Inka empire: new perspectives on territorial and hegemonic strategies of domination. Journal of Anthropological Archaeology 27: 63-81.

Arriaza, B.; J. P. Ogalde, J. Chacama, V. Standen, L. Huamán \& F. Villanueva, 2015. Estudio de almidones en queros de madera del norte de Chile relacionados con el consumo de chicha durante el Horizonte Inka. Estudios Atacameños 50: 59-84.

Barthel, T., 1970. Erste Schritte zur Entzifferung der Inka Schrift. Tribus 19: 91-96.

Belmar, C., L. Quiroz \& X. Albornoz, 2013. Análisis de residuos: microfósiles asociados al contenido de piezas cerámicas procedentes de los sitios estadio de Quillota, El Tártaro y Pocuro 11. En Informe año 4 y final FONDECYT 1090680, Pavlovic, D.; R. Sánchez \& A. Troncoso.

Belmar, C., L. Quiroz \& C. CARrasco, 2015 Ms. Informe arqueobotánico preliminar del sitio quilicura 1: análisis de evidencia microfósiles y carporrestos.

BraY, T., 2003. To dine splendidly. Imperial pottery, commensal polities, and the Inka State. En The Archaeology and politics of food and feasting in early states and empire. T. Bray, Ed., pp. 93-142. Nueva York: Springer us.

BRAY, T., 2004. La alfarería imperial Inka: Una comparación entre la cerámica estatal del área de Cuzco y la cerámica de las provinicas. Chungara 36 (2): 365-374.

BRAY, T., 2008. Las dimensiones simbólicas del poder dentro del imperio Inka. Lenguajes visuales de los Inkas, P. González \& T. Bray, Eds., pp. 13-19. Oxford: BAR International Series 1849.

CÁceres, I.; C. GonzÁlez, I. Correa, R. Retamal, M. RodríGUEZ \& M. SAAVEDRA, 2010. Carrascal 1: nuevos aportes a la discusión sobre la presencia Inka en Chile central. En Actas del XviI Congreso Nacional de Arqueología Chilena, tomo 1, pp. 331-340.

Cantaruti, G. \& R. Mera, 2002. Alfarería del cementerio estación Matucana: ensayo de clasificación y relaciones con la cerámica del período Inca de Chile central y áreas vecinas. Werkén 3: 147-170. 
Ceruti, M., 2003. Llullaillaco: sacrificios y ofrendas en un santuario inca de alta montaña. Salta: Instituto de Investigaciones de Alta Montaña, Universidad Católica de Salta.

Contreras, H., 2000 Ms. Empresa colonial y servicio personal en la encomienda de Putaendo, La Ligua y Codegua, 1549-1630. Informe Final proyecto FONDECYT 1970531.

Correa, I.; F. Bahamondes, M. Uribe, \& C. Solervicens, 2007-2008. Contextos alfareros de interacción social: lo local y lo foráneo en el cementerio Inca de Quinta Normal. Revista de Antropología 19: 143-171.

Cummins, T., 2004. Brindis con el Inka. La abstracción andina y las imágenes coloniales de los queros. Lima: Universidad Nacional Mayor de San Marcos-Universidad Mayor de San Andrés-Embajada de los Estados Unidos de América.

Cummins, T., 2007. Queros, aquillas, uncus, and chulpas: the composition of Inka artistic expression and power. En Variations in the expression of Inka power, R. Burger, C. Morris \& R. Matos, Eds., pp. 267-311. Dumbarton Oaks: Harvard University Press.

Cummins, T., 2015. Inka art. En The Inka empire. A multidisciplinary approach, I. Shimada, Ed., pp. 165-196. Austin: University of Texas Press.

De La JARA, V., 1967. Vers le déchiffrement des écrituresanciennes du Pérou. Science et Progrés 338: 241-247.

Dillehay, T., 2003. El colonialismo Inka, el consumo de chicha y los festines desde una perspectiva de banquetes políticos. Boletín de Arqueología 7: 335-365. Lima: Pontificia Universidad Católica del Perú.

Eeckhout, P. \& N. DANis, 2004. Los tocapus reales en Guaman Poma: ¿una heráldica Incaica? Boletín de Arqueología 8: 305-323. Lima: Pontificia Universidad Católica del Perú.

Falabella, F.; D. Pavlovic, M. Planella \& L. Sanhueza, 2016. Diversidad y heterogeneidad cultural y social en Chile Central durante los Períodos Alfarero Temprano e Intermedio Tardío (300 años A.C. a 1.450 años D.c.). En Prehistoria en Chile. Desde sus primeros habitantes hasta los Incas, F. Falabella, M. Uribe, L. Sanhueza, C. Aldunate \& J. Hidalgo, Eds., pp. 365-399. Santiago: Universitaria.

Fernández BACA, J., 1971. Motivos de ornamentación de la cerámica Inca del Cuzco. Lima: Librería Stadium.

Flores, J., E. Kuon \& R. SAmanéz, 1998. Queros, arte inca en vasos ceremoniales. Lima: Banco de Crédito del Perú, Colección Arte y Tesoros del Perú.

GARCEAU, C., 2009. Lo cotidiano, lo simbólico y la integración del Sitio Tambo Ojos de agua en la Región sur del Tawantinsuyu. Cordillera del Aconcagua. Memoria para optar al Título de Arqueólogo. Departamento de Antropología, Facultad de Ciencias Sociales, Universidad de Chile.

Garcilaso de la Vega, 1982 [1609]. Comentarios reales de los Inkas, tomo II. Buenos Aires: Emecé.

GonzÁlez, C. \& A. Rodríguez, 1993. Análisis de las prácticas mortuorias incaicas en Chile central. En Actas del XII Congreso Nacional de Arqueología Chilena, tomo II, pp. 223-234.
Guamán Poma de Ayala, F., 1988 [1615]. El primer nueva crónica y buen gobierno. J. V. Murra \& R. Adorno, Eds. México DF: Siglo XxI.

Hastorf, C., 2003. Andean luxury foods: special food for the ancestors, deities and the élite. Antiquity 297: 545-554.

HAYASHIDA, F., 2003. Leyendo el registro arqueológico del dominio Inka: Reflexiones desde la costa norte del Perú. Boletín de Arqueología 7: 305-319. Lima: Pontificia Universidad Católica del Perú.

Hermosilla, N., C. González \& D. Baudet, 2002-2005. Sitio Peldehue: rescate de un contexto funerario Inka en un sitio habitacional Aconcagua. Xama 15-18: 263-278.

HorTA, H., 2008. Insignias para la frente de los nobles Incas: una aproximación etnohistórica-arqueológica al principio de la dualidad. En Lenguajes visuales de los Inkas. P. González \& T. Bray, Eds. Oxford: BAR International Series 1849.

Horta, H., 2013. Queros de madera del Collasuyu: nuevos datos arqueológicos para definir tradiciones (s. XIV-XVI). Estudios Atacameños 45: 95-116.

Letelier, J., 2010. Arquitectura y espacio: estrategias de dominación incaica en el Valle del Aconcagua, v Región. Memoria para optar al título del Arqueóloga, Universidad Internacional sEK, Facultad de Estudios del Patrimonio Cultural y Arqueología, Santiago.

Liebscher, V., 1986. La iconografía de los queros. Lima: Herrera Editores.

LizÁrraga, M., 2009. Las élites andinas coloniales y la materialización de sus memorias particulares en los queros de la transición (vasos de madera del siglo xvi). Boletín del Museo Chileno de Arte Precolombino 14 (1): 37-53.

MADRID, J. \& A. GoRdon, 1964. Reconocimiento del sitio Jardín del Este, Vitacura, Provincia de Santiago. En Actas del III Congreso Internacional de Arqueología Chilena, pp. 185-189.

MANKUK, 2015 Ms. Informe Rescate arqueológico Sitio Talleres y Cocheras (TyC-1).

Martínez, J. L., 1986. El personaje sentado en los keru. Hacia una identificación de los kuraka andinos. Boletín del Museo Chileno de Arte Precolombino 1: 101-124.

Martínez, J. L., C. Díaz, C. Tocornal \& V. Arévalo, 2014. Comparando las crónicas y los textos visuales andinos. Elementos para un análisis. Chungara 46 (1): 91-113.

Martínez, A., 2011. Reevaluación del sitio Cerro La Cruz. Su función en las estrategias de dominio inkaico en el curso medio del Aconcagua. Memoria para optar al título de Arqueóloga. Departamento de Antropología, Facultad de Ciencias Sociales, Universidad de Chile.

Matos, R., 1999. La cerámica inca. En Los Incas. Arte y simbolismo, C. Morris, F. Pease \& J. Santillana, Eds., pp. 109-165. Lima: Banco de Crédito del Perú.

Mostny, G., 1946-1947. Un cementerio incásico en Chile central. Boletín del Museo Nacional de Historia Natural 23: 17-41.

NuÑEZ, L., 1963. Los queros del norte de Chile. Antropología 1: $72-88$. 
Pavlovic, D.; A. Troncoso, R. Sánchez \& D. Pascual, 2012. Un tigre en el valle. Vialidad, arquitectura y ritualidad incaica en la cuenca superior del río Aconcagua. Chungara 49 (4): 551-569.

Pavlovic, D., R. SÁnchez \& A. Troncoso, 2013 Ms. Informe año 4 y final FONDECYT 1090680.

Pavlovic, D.; D. Pascual, C. Cortés, A. Martínez, M. Albán, C. Dávila, E. Rosende \& F. Villela, 2014. Formas de ocupación del espacio en el valle de Aconcagua durante los Períodos Intermedio Tardío y Tardío. Distribución espacial en sociedades no aldeanas: del registro arqueológico a la interpretación social. F. Falabella, L. Sanhueza, L. Cornejo, I. Correa, Eds., 4: 117-141. Serie Monográfica de la Sociedad Chilena de Arqueología.

Pavlovic, D.; R. Sánchez, D. Pascual \& A. Martinez, 2016. Dinámicas de interacción. Sociedades segmentarias y el Tawantinsuyu en la frontera sur del Collasuyu. Manuscrito presentado en Taller "Repensando el Inka", F. Hayashida, A. Troncoso \& D. Salazar. Dumbarton Oaks: Harvard University Press.

Perales, M., 2004. El control inka de las fronteras étnicas: reflexiones desde el valle de Ricrán en la sierra central del Perú. Chungara 36: 515-524.

Ramos, M. A., 2015. Un kero inka en Huaycán de Cieneguilla, objeto simbólico de prestigio y reciprocidad en un contexto funerario. <http://repositorio.cultura.gob.pe/bitstream/ handle/CULTURA/306/2015.08.21\%20Kero\%20Inca\%20 en\%20Huayc\%C3\%A1n\%20de\%20Cieneguilla\%20-\%20 Objeto\%20de\%20Prestigio\%20y\%20Reciprocidad\%20 $\% 28$ Ramos\%29.pdf? sequence $=1$ \&isAllowed $=y>$ [Consultado 29-07-2017].

Reyes, V.; M. Henríquez, J. Sanhueza \& C. Prado, 2012. Cementerio inkaico estación Quinta Normal, sector Matucana, Santiago de Chile: nuevos antecedentes. Actas del XVIII Congreso Nacional de Arqueología Chilena, pp. 487-495.

SAIgnes, T., 1993. Borracheras andinas. ¿Por qué los indios ebrios hablan en español? En Borrachera y Memoria. La experiencia de lo sagrado en los Andes, T. Saignes, Comp., pp. 43-72. La Paz: Hisbol-Instituto Francés de Estudios Andinos.

SÁnchez, R., 2003. El fin de la Cultura Aconcagua y su relación con el Tawantinsuyu. En Actas IV Congreso Chileno de Antropología, vol. 2: 1432-1437.

SÁnchez, R., 2004. El Tawantinsuyu en Aconcagua (Chile Central). Chungara 36 (2): 325-336.

Sánchez, R.; D. Pavlovic, P. González \& A. Troncoso, 2004. Curso superior del río Aconcagua. Un área de interdigitación cultural. Períodos Intermedio Tardío y Tardío. Chungara 36 (2): 753-766.

SAnhueza, L., 2001. El aríbalo inca en Chile central. Werkén 2: 47-69.

Stehberg, R., 1976. La fortaleza de Chena y su relación con la ocupación incaica de Chile central. Publicación Ocasional del Museo Nacional de Historia Natural (Chile) 23: 3-37.
STEHBERG, R., 1995. Instalaciones incaicas en el norte y centro semiárido de Chile. Centro de Investigaciones Diego Barros Arana. Santiago de Chile: Dibam.

Stehberg, R. \& G. Sotomayor, 2012. Mapocho inkaico. Boletín del Museo Nacional de Historia Natural 1: 85-149.

Thomas, C.; M. Benavente, C. Massone, N. Gaete, R. Sánchez, G. Serracino, D. Jackson, C. Becker, J. Hagn, F. Constantinescu \& R. Izaurieta, 1990. Informe año 2 FONDECYT 1240-88.

Troncoso, A.; F. Criado-Boado \& M. Santos-Estévez, 2011. Arte rupestre y códigos espaciales: un caso de estudio en chile central. Chungara 43 (2): 161-176.

Troncoso, A.; D. Pavlovic, F. Acuto, R. Sánchez \& A. GonZÁLEZ-GARCíA, 2012. Complejo arquitectónico cerro Mercachas: arquitectura y ritualidad incaica en Chile central. Revista Española de Antropología Americana 42 (2): 293-319.

VÁsquez, M., 1994. Contextos cerámicos incaicos en Chile central. En Actas del II Taller de Arqueología de Chile Central. <http://www.arqueologia.cl/actas2/vasquez.pdf > [Consultado 30-07-2017].

WiLLIAMs, V., 2008. Espacios conquistados y símbolos materiales del Imperio Inka en el Noroeste de Argentina. Lenguajes visuales de los Inkas. P. González \& T. Bray, Eds., pp. 47-70. Oxford: BAR International Series 1849.

Zıólkowski, M., 1979. Acerca de algunas funciones de los keros y los akillas en el TawantinsuyuInkaico y en el Perú Colonial. Estudios Latinoamericanos 5: 1-24.

ZıólKowski, M., 1996. La guerra de los wawqi: los objetivos y los mecanismos de la rivalidad dentro de la elite inka, siglos XV-XVI. Quito: Abya-Yala.

Ziólkowski, M.; J. Arabas \& J. Szeminski, 2008. La historia de los queros: apuntes acerca de la relación entre las representaciones figurativas y los signos Tocapus. Lenguajes visuales de los Inkas. P. González \& T. Bray, Eds. pp. 163 176. Oxford: BAR International Series 1849.

Zuidema, T., 1991. La civilización Inka en Cuzco. México DF: Fondo de Cultura Económica. 
